\title{
Cangju Qinggan Jiangzhi Decoction Reduces the Development of Non- Alcoholic Steatohepatitis and Activation of Kupffer Cells
}

\author{
Yang Cheng ${ }^{a, b} \quad$ Tianyang Chen ${ }^{b} \quad$ Jian Ping ${ }^{b} \quad$ Jianjie Chen ${ }^{a, b}$ \\ aHospital for Infectious Diseases of Pudong New Area, Shanghai, 'Institute of Liver Disease, Shuguang \\ Hospital Affiliated to Shanghai University of Traditional Chinese Medicine, Shanghai, P. R. China
}

\section{Key Words}

Cangju Qinggan Jiangzhi decoction $•$ Nonalcoholic steatohepatitis $•$ Metabolic disease $\bullet$ Highfat-diet $•$ MCD diet - NAFLD

\begin{abstract}
Background/Aims: Nonalcoholic steatohepatitis (NASH) is defined as lipid accumulation with hepatic injury, inflammation and early to moderate fibrosis. Kupffer cells play a crucial role in promoting hepatic inflammation, which further facilitates the development of NASH. Here we investigated the effects of Cangju Qinggan Jiangzhi decoction (CQJD) on high fat diet (HFD) and methionine-choline deficient (MCD) induced mouse NASH pathogenesis. Methods: Mouse NASH models were developed by HFD and MCD diet. The treated mice were divided into three groups: the control group $(n=10)$, the low-dose CQJD treatment group $(n=10)$ and the highdose CQJD treatment group $(n=10)$. The hepatic injury, inflammation, and apoptotic molecules were evaluated by H\&E staining, immunohistochemistry and real-time PCR. Kupffer cells were isolated from control mice and CQJD-treated mice after stimulation by lipopolysaccharide (LPS) and/or palmitic acid. The level of the inflammatory cytokines TNF $\alpha$, IL1 $\beta$, and CCL2 was measured by ELISA. Results: The HFD-fed mice displayed significant metabolic, inflammatory, and oxidative stress-related alterations due to hepatic lipid accumulation. CQJD treatment largely normalized the hepatic injury, lowered the ALT/AST level, and reduced the severity of liver inflammation, as revealed by the decreased inflammatory cytokines levels. In vitro, CQJD blocked the activation of LPS- or palmitic acid-primed Kupffer cells in a dose-dependent manner. In the MCD diet-induced NASH mice, similar therapeutic effects of CQJD were also observed. Conclusion: CQJD ameliorates mouse nonalcoholic steatohepatitis. The reduction in liver injury and inflammation induced by CQJD is associated with reduced activation of Kupffer cells. Our results suggest that CQJD is a promising therapeutic strategy in clinical steatohepatitis.




\section{Cellular Physiology Cell Physiol Biochem 2018;48:971-982 \\ \begin{tabular}{ll|l} 
and Biochemistry Publisned ontIne: July 23, 2018 & $\begin{array}{l}\text { D } 2018 \text { The Author(s). Published by S. Karger AG, Basel } \\
\text { www.karger.com/cpb }\end{array}$ \\
\hline
\end{tabular} \\ Cheng et al.: Cangju Qinggan Jiangzhi Decoction Inhibits NASH Development}

\section{Introduction}

Non-alcoholic fatty liver disease (NAFLD) is a metabolic liver disease associated with insulin resistance (IR) and genetic predisposition. NAFLD is divided into the histological categories of non-alcoholic fatty liver (NAFL) and nonalcoholic steatohepatitis (NASH). NASH is considered the progressive subtype of NAFLD and is distinguished from NAFL by the additional presence of hepatic injury with or without fibrosis [1-4]. Current dynamic liver biopsy data and cohort studies have shown that the natural outcome of NAFLD largely depends on the type of liver histology. Patients with NAFL often have quiescent liver disease with an incidence of cirrhosis of 0.6-3\% at 10-20 years of follow-up. The incidence of cirrhosis in patients with NASH is $15-25 \%$ within 10 years. Additionally, NASH is one of the important causes of clinical cryptogenic cirrhosis [5, 6]. Approximately $30 \%$ to $40 \%$ of NASH patients progress to advanced liver fibrosis, $10 \%$ to $15 \%$ progress to cirrhosis, and $3 \%$ eventually progress to liver failure [7]. Although the progression of liver fibrosis is relatively slower in patients with NASH than in patients with chronic viral hepatitis and primary biliary cirrhosis, the prognosis of NASH-related cirrhosis is similar to that for causes of cirrhosis and patients with NASH may be more susceptible to aging and metabolic syndrome-related liver failure and hepatocellular carcinoma [8-10]. Therefore, identification of cellular and molecular processes of NASH pathogenesis is of great importance to identify novel therapeutic targets for this highly prevalent and potentially serious disease [11-13].

Kupffer cells, the liver-resident macrophages, originate from the myelomonocytic population, colonize in the liver sinusoids, and account for $20 \%$ of non-parenchymal cells in the liver [14]. Accumulated studies have shown that Kupffer cells are the most important immune cells in the pathogenesis of NAFLD and are also the core cells of the inflammatory mediators of obesity and insulin resistance [15-17]. Kupffer cells are the first defensive barrier in the liver and play an important role in the innate immunity of the liver via Toll-like receptor (TLR) signaling [18]. Activated Kupffer cells can participate in the pathogenesis of NAFLD through a variety of pathways [19-22]. First, activated Kupffer cells interact with other liver cells, including hepatocytes, and release various bioactive substances such as cytokines, chemoattractants, proteolytic enzymes, and reactive oxygen species (ROS) to induce biochemical attacks [5, 23]. Second, activated Kupffer cells can lead to a secondary inflammatory response by secreting chemokines and expressing adhesion receptors to recruit neutrophils, T lymphocytes, NK cells, and blood monocyte-derived macrophages to the liver $[5,23]$. Thus, targeting the activation of Kupffer cells might be a key approach for suppressing NASH progression [19].

Cangju Qinggan Jiangzhi decoction (CQJD), a traditional Chinese medicine (TCM) prescription formulated in our hospital, consist of Atractylodes chinensis (6 g), fried atractylodes (10 g), lotus leaf (10 g), cassia (10 g), chrysanthemum (10 g), and Typha angustifolia (6 g). CQJD has been used to treat NAFLD in our hospital and provoded a good outcome. CQJD can effectively improve the patient's symptoms and laboratory biochemical indicators. In addition, our previous experiments showed that CQJD can effectively improve the liver steatosis and inflammatory liver damage degree in a $\mathrm{CCl}_{4}$-induced liver fibrosis mouse model (article in Chinese). However, little is known about whether CQJD produces a protective effect against $\mathrm{NASH}$, and its related underlying mechanisms remain to be elucidated.

In this study, we sought to investigate the potential therapeutic role of CQJD in the regulation of Kupffer cell activation and NASH pathogenesis. High fat diets (HFD) and obesity lead to a chronic state of low-grade inflammation, increased ROS production and cell death. Therefore, we first tested whether CQJD plays a role in the pathogenesis of HFD-induced liver injury. Using this in vivo model, we observed a dose-dependent protective effect of CQJD on liver injury, lipid accumulation, inflammation, and mitochondrial oxidative stress in the liver. Moreover, to further enhance the translational potential of our study, we also determined the role of CQJD in a methionine and choline deficient (MCD) diet-induced NASH mouse model [24]. 


\section{Cellular Physiology Cell Physiol Biochem 2018;48:971-982 \begin{tabular}{ll|l} 
and Biochemistry Published onlIne: July 23, 2018 & $\begin{array}{l}\text { C } 2018 \text { The Author(s). Published by S. Karger AG, Basel } \\
\text { www.karger.com/cpb }\end{array}$
\end{tabular} \\ Cheng et al.: Cangju Qinggan Jiangzhi Decoction Inhibits NASH Development}

\section{Materials and Methods}

\section{NASH mouse model}

The high fat diet induced NASH mouse model was reported previously [25]. Briefly, male C57BL/6J mice (20 to 25 g body weight) at ages of 8-12 weeks were purchased from the Shanghai Center of Laboratory Animals. All surgical and care procedures administered to the animals were in accordance with the institutional guide lines of the Shanghai Center of Laboratory Animals. All mice were housed at $21 \pm 1^{\circ} \mathrm{C}$ with a humidity of $55 \pm 10 \%$ and a 12-hr light/12-hr dark cycle with free access to food and water. Once the mice had adapted to the environment, the C57BL/6J mice in the normal control group were fed a standard chow diet, while the others were fed the HFD (approximately $1.67 \mathrm{kcal} / \mathrm{g}$ ), which was composed of 79.5\% corn powder, $0.5 \%$ cholesterol and $20 \%$ lard. For the generation of the methionine and choline deficient diet (MCD) mouse model, groups $(\mathrm{n}=8)$ of 8-week-old male C57BL/6J mice were placed on the MCD diet, while controls were fed the same diet supplemented with methionine and choline.

\section{Preparation of CQJD}

CQJD consisted of the following six crude medical herbs: Atractylodes chinensis (6 g), fried atractylodes (10 g), lotus leaf (10 g), cassia (10 g), chrysanthemum (10 g), and Typha angustifolia ( $6 \mathrm{~g})$. The extraction was performed by a skilled and certified pharmacologist and assisted by the Experimental Center of Shanghai University of Traditional Chinese Medicine. Each drug was extracted by supercritical fluid extraction with carbon dioxide, and then dissolved in distilled water at the desired concentrations. For the generation of CQJD medical serum, twenty normal SD male rats (6-8 weeks) were randomly divided into a control group and a CQJD group. The CQJD group was given an intragastric administration of $10 \mathrm{~mL} / \mathrm{kg}$ rat body weight, which is equivalent to 7 times the dose for a $60 \mathrm{~kg}$ human; the control group was given the corresponding amount of distilled water; the treatment was performed 2 times a day for 3 days. Fasting was performed on the 3rd day after gavage, and gavage was performed again in the next morning. After $1 \mathrm{~h}$, blood was collected from the posterior vena cava under aseptic conditions and allowed to stand for 3 to $4 \mathrm{~h}$ at $4^{\circ} \mathrm{C}$, followed by centrifugation at $3000 \mathrm{rpm}$ for $20 \mathrm{~min}$. The serum was separated on a clean bench. The isolated serum was placed in $56^{\circ} \mathrm{C}$ water bath for $30 \mathrm{~min}$ to inactivation, and stored at $-70^{\circ} \mathrm{C}$ in a refrigerator.

\section{Food intake and body weight}

The Food intake and mouse body weight were recorded daily. To determine the effect of CQJD on food intake, the mice were maintained on the HFD (11 weeks) and were treated with $10 \mathrm{mg} / \mathrm{kg}$ CQJD (low), 50 $\mathrm{mg} / \mathrm{kg}$ CQJD (high), or vehicle for an additional 8 days.

\section{Isolation of Kupffer cells}

Kupffer cells were isolated via a two-step collagenasepronase perfusion of mouse livers followed by 15\% Nycodenz (Sigma, D2158, Shanghai, China) two-layer discontinuous density gradient centrifugation. The purity of the cultures was assessed by flow cytometric analysis and magnetic antibody cell sorting (anti-F4/80 antibody). Isolated Kupffer cells were cultured for $24 \mathrm{~h}$ in Dulbecco's modified eagle's medium (DMEM) containing 10\% fetal bovine serum and 1\% antibiotics $(100 \mathrm{U} / \mathrm{ml}$ penicillin and 100 $\mu \mathrm{g} / \mathrm{ml}$ streptomycin) in a humidified incubator at $37^{\circ} \mathrm{C}$ with $5 \% \mathrm{CO}_{2}$. For activation of Kupffer cells, Lipopolysaccharide (LPS) (1 ng/mL; Sigma; L2880) and/or palmitic acid (400 $\mu$ M; Sigma; P5585) were added to the culture medium, and the cells were further stimulated for $12 \mathrm{~h}$. The cells were pre-treated with CQJD for $2 \mathrm{~h}$ prior to the administration of LPS or palmitic acid.

\section{Quantitative real-time PCR}

Total RNA was extracted from cells or tissues using the standard TRIzol method according to the manufacturers' instructions (Invitrogen, Shanghai). The concentration of total RNA was quantified by a NanoDrop 2000 spectrophotometer (Thermo Fisher Scientific Inc) followed by reverse transcription using the a RT first-strand cDNA synthesis kit for RT-PCR. Real-time PCR was performed using a SYBR Green Premix Ex Taq (Takara, Japan) in a $20 \mu \mathrm{L}$ reaction system. The relative expression level of mRNA was determined by normalizing to an internal invariant control $\beta$-actin. Each reaction was performed in triplicate. The primers used in this study were shown as follows: Ly6G forward, 5'-AACTCCCAGTTGGTCGGGAT-3', Ly6G reverse: 5'-GTTGAGGTTTGCGGTCCAG-3'; TNF $\alpha$ forward, 5'-CCTGTAGCCCACGTCGTAG-3', TNF $\alpha$ reverse: 


\section{Cellular Physiology Cell Physiol Biochem 2018;48:971-982 \begin{tabular}{l|l} 
DOI: 10.1159/000491965 & and Biochemistry Publisned onlme: 2018 The Author(s). Published by S. Karger AG, Basel \\
www.karger.com/cpb
\end{tabular}}

Cheng et al.: Cangju Qinggan Jiangzhi Decoction Inhibits NASH Development

5'-GGGAGTAGACAAGGTACAACCC-3'; IFN $\gamma$ forward, 5'-ATGAACGCTACACACTGCATC-3', IFN $\gamma$ reverse: 5'-CCATCCTTTTGCCAGTTCCTC-3'; CXCL2 forward, 5'-CCAACCACCAGGCTACAGG-3', CXCL2 reverse: 5'-GCGTCACACTCAAGCTCTG-3'; CCR2 forward: 5'-TGTGATTGACAAGCACTTAGACC-3'; CCR2 reverse, 5'-TGGAGAGATACCTTCGGAACTT-3', IL1 $\beta$ forward, 5'-GCAACTGTTCCTGAACTCAACT-3', IL1 $\beta$ reverse: 5'-ATCTTTTGGGGTCCGTCAACT-3'; MIP1 $\alpha$ forward, 5'-TTCTCTGTACCATGACACTCTGC-3', MIP1 $\alpha$ reverse: 5'-CGTGGAATCTTCCGGCTGTAG-3'; gp91 phox forward, 5'-TGTGGTTGGGGCTGAATGTC-3', gp91 phox reverse: 5'-CTGAGAAAGGAGAGCAGATTTCG-3'; p47 phox forward, 5'-ACACCTTCATTCGCCATATTGC-3', p47 phox reverse: 5'-TCGGTGAATTTTCTGTAGACCAC-3'; iNOS forward, 5'-GGAGTGACGGCAAACATGACT-3', iNOS reverse: 5'- TCGATGCACAACTGGGTGAAC-3'; ACTA2 forward, 5'-GTCCCAGACATCAGGGAGTAA-3', ACTA2 reverse: 5'-TCGGATACTTCAGCGTCAGGA-3'. COL1A1 forward, 5'-GCTCCTCTTAGGGGCCACT-3', COL1A1 reverse: 5'-CCACGTCTCACCATTGGGG-3'.

\section{Hematoxylin and eosin staining}

Liver tissue was fixed in $10 \%$ formalin and embedded in paraffin. Fresh liver tissue was frozen in optimum cutting temperature (OCT) compound on dry ice, and cryosectioned into $5 \mu \mathrm{m}$ sections. The liver specimens were evaluated by light microscopy.

\section{Measurement of liver triglycerides}

Harvested liver tissues were homogenized in chloroform/methanol $(2: 1 \mathrm{v} / \mathrm{v})$ using a Polytron tissue grinder and lipid extracts were prepared by the classical Folch method as previously reported [10]. The extracts were dried and dissolved in isopropanol. Liver triglyceride levels were measured biochemically using the Triglyceride Reagent Kit (Jiancheng Bioeng. Com., Nanjing, China).

\section{Measurement of serum ALT and AST}

The obtained blood samples were kept at room temperature for $1 \mathrm{~h}$. Serum was then collected after centrifugation at $840 \times \mathrm{g}$ for $15 \mathrm{~min}$. The plasma alanine amino transferase (ALT) and aspartate amino transaminase (AST) activity was measured using a commercial kit from Rsbio (Shanghai, China) according to the manufacturer's instructions.

Detection of Caspase-3/7 activity

Caspase-3/7 activities were also measured using the Apo-ONE Homogeneous Caspase-3/7 assay kit (Promega, Madison, WI) according to the manufacturer's instructions.

\section{Measurement of MPO activity}

The activity of MPO was determined based on the reaction of hypochlorous acid with taurine to produce taurine chloramine and the subsequent measurement of this oxidant using the 3, 3',5, 5'-tetramethylbenzidine reagent according to the manufacturer's instructions (Sigma-Aldrich, Shanghai, China).

\section{Measurement of $M_{1} d G$}

In brief, DNA was isolated by standard techniques. The quantity and quality of DNA was measured using a Nanodrop 1000 spectrophotometer (Thermo Scientific, USA). The 32P-post labelling technique was used to measure the levels of 3-(2-deoxy- $\beta$-d-erythro-pentofuranosyl)pyrimido [1, 2- $\alpha$ ]purin-10(3H)-one (M1dG). Detection and quantification of M1dG adducts and total nucleotides were acquired by phosphor imaging system (Typhoon 9210, Amersham) and ImageQuant software (Molecular Dynamics, Sunnyvale, CA).

\section{Measurement of 4-HNE and 3-NT}

The levels of liver 4-HNE were measured by using a commercial kit from (Cell Biolabs, USA). Briefly, BSA or hepatic tissue homogenates $(10 \mu \mathrm{g} / \mathrm{ml})$ were absorbed on to 96 -well plates. The HNE in the tissue samples was captured with anti 4-HNE antibody, followed by an HRP-conjugated secondary antibody. The level of 4-HNE in the samples was determined based on a standard curve generated with BSA-HNE according to the manufacturer's instructions. For detection of hepatic 3-NT levels, a commercial ELISA kit from Abcam (ab116691, Shanghai, China) was used. 


\section{Cellular Physiology Cell Physiol Biochem 2018;48:971-982

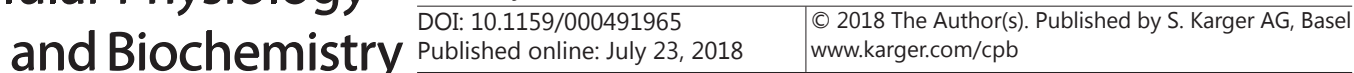

ELISA analysis of TNF $\alpha, I L 1 \beta$, and CCL2

With ELISA test, TNF $\alpha$, IL1 $\beta$, and CCL2 levels were measured from cell culture supernatants by mouse immunoassays (R\&D Systems, Minneapolis, MN), according to the manufacturer's instructions.

\section{Statistical analysis}

Data are shown as the means \pm SDs. The calculations were performed using GraphPad Prism version 4.03 for Windows (GraphPad Software Inc., San Diego, CA). Two-tailed unpaired Student's t-tests were used for comparisons of two groups. The ANOVA multiple comparison test was used for comparisons of more than two groups. Differences were considered to be statistically significant at $\mathrm{p}<0.05$.

\section{Results}

\section{CQJD attenuates HFD-induced steatohepatitis}

In this study, we first explored the potential therapeutic efficacy of CQJD in an HFD mouse model of NASH. Examination of the liver histology of HFD mice (control group) demonstrated significant steatosis, hepatocyte ballooning and parenchymal inflammatory infiltrates, which were alleviated by CQJD in a dose-dependent manner (Fig. 1A). Treatment of the HFD mice with CQJD also significantly decreased the hepatic lipid accumulation (Fig. 1B). Additionally, the histologic improvement induced by CQJD was associated with a remarkable reduction in serum alanine amino transferase (ALT) and aspartate amino transaminase (AST) activity (Fig. 1C). Notably, we also measured the effects of CQJD on hepatocyte apoptosis. As shown in Fig. 1D and 1E, the levels of DNA fragmentation and caspase $3 / 7$ activity, two markers of cell apoptosis, were also reduced by treatment with CQJD in a dosedependent manner.

\section{CQJD treatment decreases} the liver mass of HFD-fed mice

To determine whether the improvement in liver injury was due to weight loss in the CQJDtreated group, we measured the food intake and body weight. The results showed comparable food intakes and final body weights between the control group and CQJD groups (Fig. 2A and 2B). Subsequently, terminal liver was separated and the liver mass in the CQJD groups was dramatically decreased compared with that in the control group (Fig. 2C). Moreover, when normalized to the whole body weight, the relative liver mass was also reduced in the CQJD-treated group (Fig. 2D). Therefore, CQJD-treated HFD mice are protected from liver injury and have a reduction in relative liver mass.

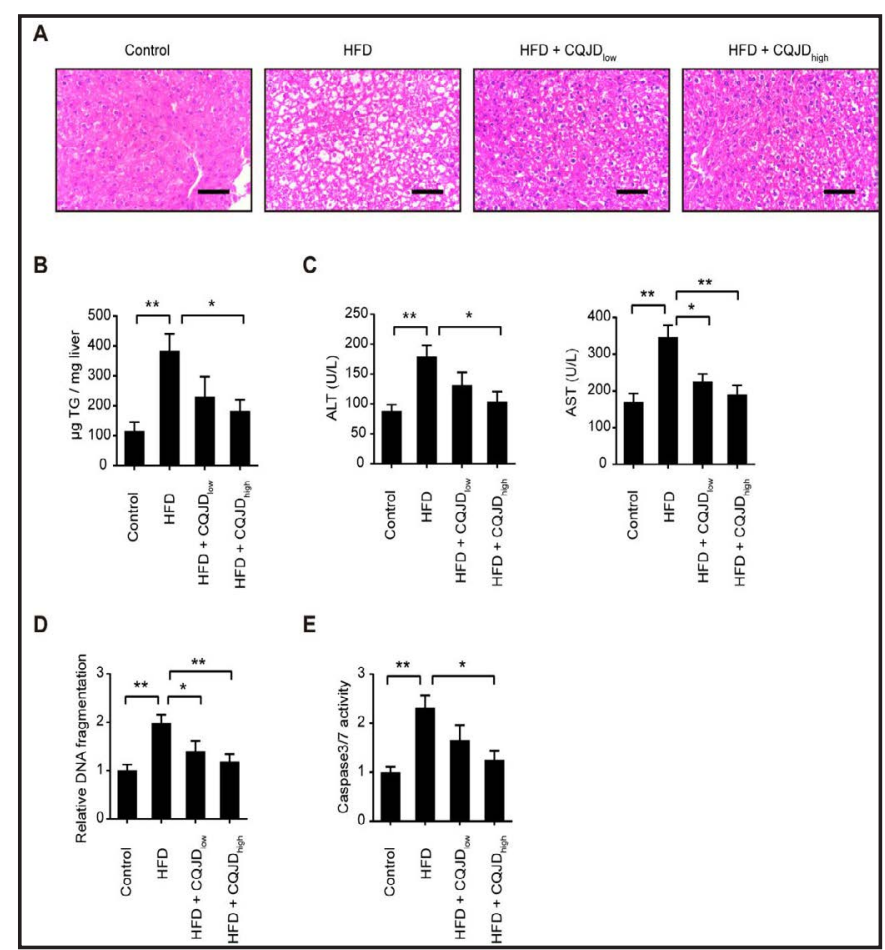

Fig. 1. CQJD attenuates HFD-induced steatohepatitis. (A) Hematoxylin\& Eosin staining of liver sections from HFD mice treated with either saline or CQJD or control chow-fed mice (Scale bar $=50 \mu \mathrm{m})$. (B) TG content in animals with fatty liver induced by HFD ( $\mathrm{n}=8)$. (C) Serum ALT and AST in the HFD mice treated with either saline or CQJD or control chow-fed mice, $n=5$ per group. (D-E) The hepatocyte apoptosis in each group was measured by the relative DNA fragmentation and caspase- $3 / 7$ activity, $n=5$ per group. ${ }^{*} \mathrm{p}<0.05$ and ${ }^{* *} \mathrm{p}<0.01$. 


\section{CQJD inhibits liver inflammation in HFD-fed mice}

NASH is viewed as a lipotoxic disorder that, can generate injurious lipid mediators and induce activation of inflammatory cells, including Kupffer cells, that further aggravate liver injury $[19,26]$. In this study, we found that the expression levels of the neutrophil marker Ly6G and pro-inflammatory cytokines / chemokines / chemokine receptors, including TNF $\alpha$, IFN $\gamma$, CXCL2, CCR2, IL1 $\beta$ and MIP1 $\alpha$ were significantly upregulated in HFD mice (Fig. 3A). Upon treatment with CQJD, the levels of these proinflammatory mediators were significantly attenuated in HFD mice in a dose-dependent manner (Fig. 3A). Moreover, the MPO activity (Fig. 3B) and $\mathrm{M}_{1} \mathrm{dG}$ adduct levels (Fig. 3C), the two indicator of neutrophilic influx in the liver, were also decreased by CQJD. Thus, CQJD is sufficient to block liver inflammation in HFD-fed mice.

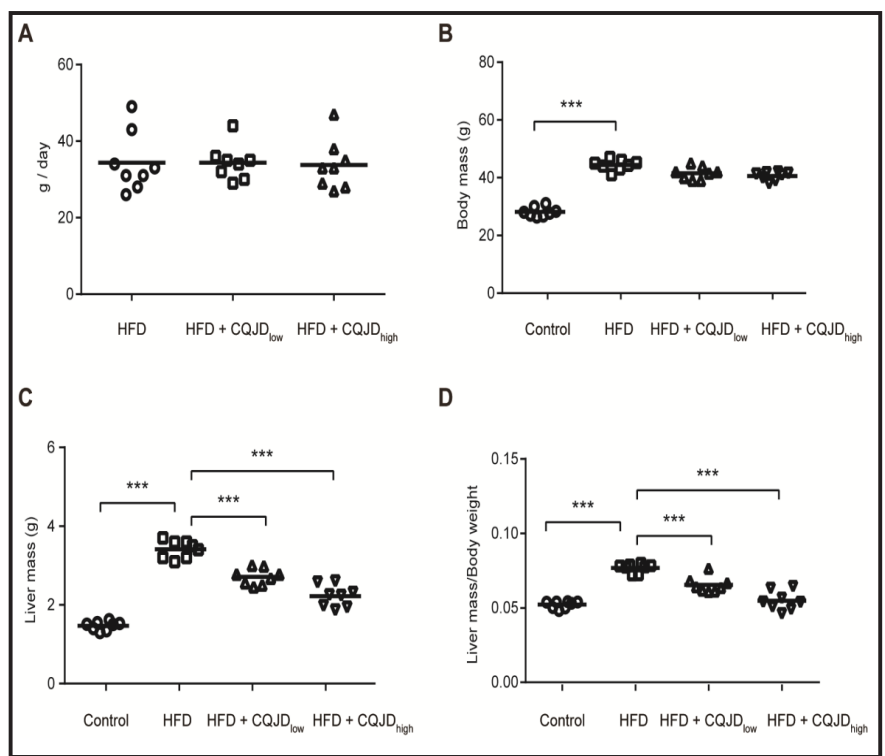

Fig. 2. CQJD treatment decreases the liver mass in HFD-fed mice. (A) Food intake was measured in the vehicle and CQJD-treated HFD-fed mice. (B-D) Final body weight (B), liver mass (C), and relative liver mass (D) of the HFD mice treated with either saline or CQJD are shown. ${ }^{* * *} \mathrm{p}<0.001$.

Fig. 3. CQJD inhibits liver inflammation in HFD-fed mice. (A) Real-time qPCR analysis of the neutrophil marker Ly6G and the inflammatory factors $\mathrm{TNF} \alpha, \mathrm{IFN} \gamma$, CXCL2, CCR2, IL1 $\beta$, MIP1 $\alpha$ and MIP2 in each group $(n=5)$. (B) The myeloperoxidase (MPO) activity in the liver of HFD mice treated with either saline or CQJD control chowfed mice ( $n=8)$. (C) The $M_{1} d G$ DNA adducts levels in each group were determined by ${ }^{32} \mathrm{P}$-postlabeling ( $\mathrm{n}$ $=8){ }^{*} \mathrm{p}<0.05$ and ${ }^{* *} \mathrm{p}<0.01$.

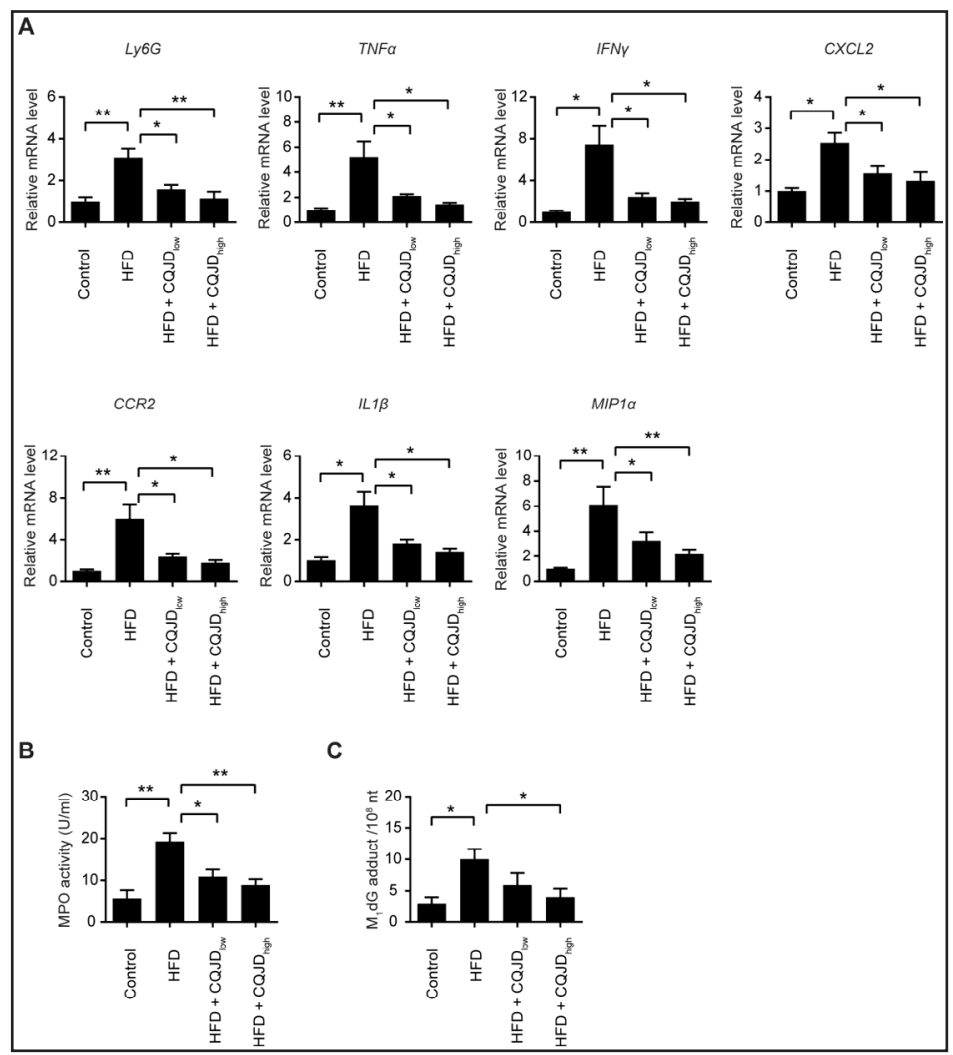


CQJD ameliorates oxidative
stress in HFD-fed mice
Apart from the intense
inflammatory

NASH is also characterized by mitochondrial oxidative stress [5, 23]. Indeed, the elevated mRNA expression levels of reactive oxygen species-generating NADPH oxidase isoforms CYBB (gp91 phox), NCF1 (p47 phox), and inducible nitric oxide synthase (iNOS) in HFD-fed mice were largely reduced by treatment with CQJD (Fig. 4A). Furthermore, the liver levels of 4-Hydroxynonenal (4-HNE) and 3-nitrotyrosine (3-NT), two markers of lipid peroxidation and oxidative and nitrative stress, were significantly decreased by CQJD treatment (Fig. 4B), indicating a reduction in mitochondrial oxidative stress.

CQJD attenuates Kupffer cell activation in vitro

Next, we investigated whether CQJD contributed to the regulation of Kupffer cell activity using primary Kupffer cell cultures. To study the NASH pathogenesis in vitro, isolated Kupffer cells were stimulated with lipopolysaccharide (LPS, $1 \mathrm{ng} / \mathrm{mL}$ ) and $400 \mu \mathrm{M}$ palmitic acid. As shown in Fig. 5, the pro-inflammatory cytokine expression of TNF $\alpha$, IL1 $\beta$, and CCL2 was markedly induced by stimulation with LPS or palmitic acid, suggesting the activation of Kupffer cells. In both the LPS- and palmitic acid-primed Kupffer cell models, the administration of CQJD effectively attenuated the cytokine expression in Kupffer cells in a dose-dependent manner (Fig. 5A and 5B). Collectively, these data above suggest that CQJD is able to inhibit Kupffer cell activation in vitro.

\section{CQJD attenuates $M C D$-induced steatohepatitis}

To further demonstrate the impact of CQJD on NASH, we evaluated its therapeutic efficiency in the methionine-choline deficient (MCD)-induced steatohepatitis mouse model. As shown in Fig. 6A, the liver injury, hepatic lipid accumulation and pro-fibrotic changes found in MCD mice were also markedly decreased by CQJD. Consistently, the plasma ALT and 


\section{Cellular Physiology and Biochemistry

AST level (Fig. 6B), as well as the levels of DNA fragmentation (Fig. 6C) and caspase-3/7 activity (Fig. 6D), were reduced by treatment with CQJD in a dose-dependent manner. Taken together, the above mentioned data suggest that CQJD plays a common role in different NASH models.

\section{Discussion}

With the continuous deepening of theoretical research and clinical research of Chinese medicine, as one of the drug treatment pathways of NAFLD, traditional Chinese medicine has certain advantages in the prevention and treatment of NAFLD [27, 28]. Previously, many Chinese decoctions, including Gegen Qinlian decoction [29], Yinchenhao decoction [30], Hua Tan Qu Shi decoction [31], Lingguizhugan decoction [32], and Qushi Huayu decoction [33], have been demonstrated to be effective in the treatment of NAFLD. For instance, Lingguizhugan decoction, a classic traditional

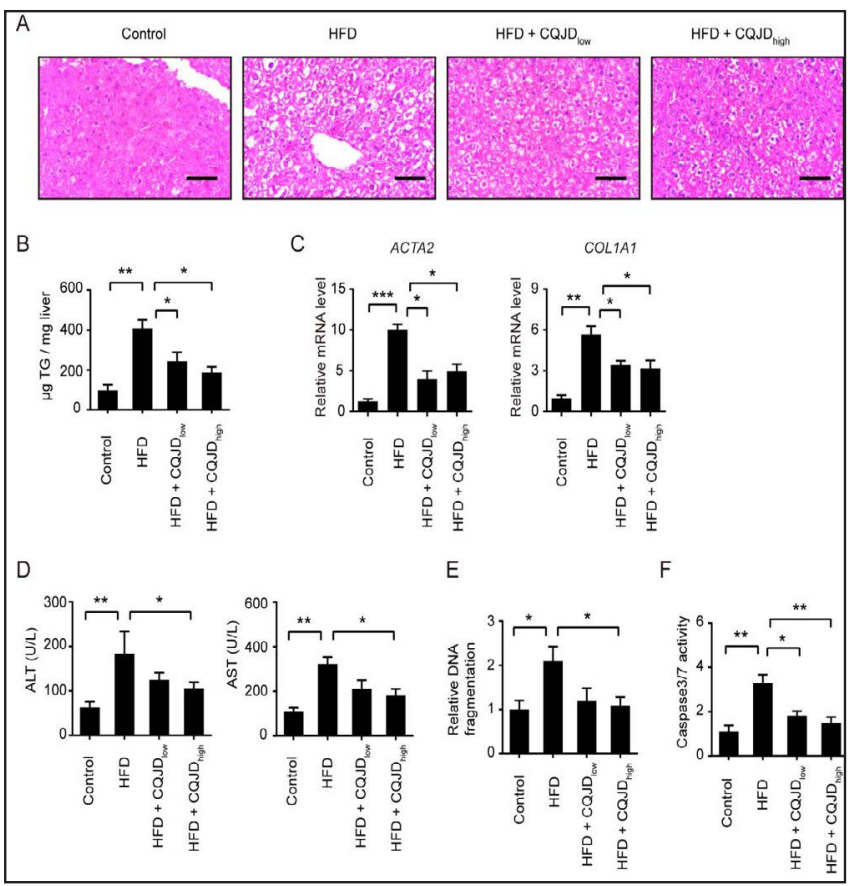

Fig. 6. CQJD attenuates MCD-induced steatohepatitis. (A) Representative HE staining of liver sections from MCD mice treated with either saline or CQJD or control chow-fed mice (Scale bar $=50 \mu \mathrm{m}$ ). (B) TG content in animals with fatty liver induced by MCD $(n=8)$. (C) Real-time qPCR analysis of the profibrotic genes ACTA2 and COL1A1 in each group ( $n=5)$. (D) Serum ALT and AST in each group, $n=5$ per group. (E-F) The hepatocyte apoptosis in the respective groups was measured by the relative DNA fragmentation and the caspase- $3 / 7$ activity, $\mathrm{n}=$ 5 per group. ${ }^{*} \mathrm{p}<0.05,{ }^{* *} \mathrm{p}<0.01$, and ${ }^{* * *} \mathrm{p}<0.001$. Chinese medicine formula, can attenuate NAFLD possibly by affecting insulin resistance and lipid metabolism-related pathways (e.g., PI3K-AKT, AMPK) [32]. In this study, we evaluated the potential effects of CQJD in HFD and MCD diet-induced NASH mouse models and found that administration of CQJD significantly attenuated NASH pathogenesis without obvious side effects such as impaired locomotor function or body weight loss in mice.

During the long course of NAFLD, NASH is the inflexion of worsening disease and is the rate-limiting and obligatory stage of cirrhosis or simple fatty liver [3]. NAFLD is a complex metabolic disease that is closely associated with visceral adiposity and insulin resistance [34, 35]. Most researchers consider that lipid accumulation in the liver is the first step but alone may not be enough to induce progressive liver injury. Additional hits including oxidative stress (such as deficiency of dietary antioxidants, glutathione depletion, and mitochondrial dysfunction), lipotoxicity, adipocytokines, activation of hepatic stellate cells, and dysregulated inflammation are potential mediators in inducing the persistent liver injury leading to the development of NASH [23, 35]. For example, Nicotinamide adenine dinucleotide (NAD), the hydrogen carrier for redox enzymes, is known for its important roles in redox reactions. $\mathrm{NAD}^{+}$levels are closely associated with energy metabolism and disease susceptibility [36]. Increasing cellular $\mathrm{NAD}^{+}$levels by treatment of the $\mathrm{NAD}^{+}$precursor, nicotinamide riboside can protect against liver injury in a SIRT1-dependent fashion [37]. In this study, we found that CQJD can protect the HFD-fed mice from the development of NASH. 


\section{Cellular Physiology Cell Physiol Biochem 2018;48:971-982 \\ \begin{tabular}{ll|l} 
and Biochemistry Publisned ontIne: July 23, 2018 & $\begin{array}{l}\text { (c) } 2018 \text { The Author(s). Published by S. Karger AG, Basel } \\
\text { www.karger.com/cpb }\end{array}$ \\
\hline
\end{tabular} \\ Cheng et al.: Cangju Qinggan Jiangzhi Decoction Inhibits NASH Development}

HFD induced inflammatory cytokine and chemokine expression was largely attenuated by CQJD treatment in a dose-dependent manner, suggesting a regulatory role for CQJD in hepatic macrophages during the progression to NASH. Kupffer cells, which constitute $80-90 \%$ of the tissue macrophages in the body, are known as an important immune cell in liver homeostasis and inflammatory diseases. Once activated, Kupffer cells play a crucial role in pathogenesis and the progression of liver disease cytokine secretion, especially TNF- $\alpha$, IL-1 $1 \beta$ and CCL2 $[19,37,38]$. In this study, we stimulated Kupffer cells with palmitic acid and LPS and found that TNF- $\alpha$, IL-1 $\beta$ and CCL2 were significantly upregulated. Notably, the secretion of these cytokines was remarkably inhibited by treatment with CQJD, suggesting that the lipotoxicity of free fatty acids as a consequence of hepatic lipid accumulation may also secondarily promote inflammation and that this connection is largely dependent on Kupffer cells.

Among the components of CQJD, several extracts have been demonstrated to play a protective role against liver injury. The main extracts of Atractylodes chinensis, Atractylone and $\beta$-eucalyptol, can effectively reduce serum ALT, AST levels in the $\mathrm{CCl}_{4}$-induced acute liver injury mouse model. Chrysanthemum extract can inhibit hepatic lipid accumulation in NAFLD mice and the mechanism may be related to increasing the anti-oxidation effect on the liver. An et al. found that lotus leaf flavonoids can inhibit the pathogenesis of NAFLD in mice by reducing the level of liver triglycerides [39]. Luo et al. reported that a component of cassia extract, anthraquinone, can prevent alcoholic fatty liver disease by regulating fat metabolism, anti-lipid oxidation, and increasing PPAR- $\gamma$ mRNA and protein expression [40]. In this study, our in vivo and in vitro experiments showed that CQJD can effectively reduce HFD and MCD diet induced NASH pathogenesis as demonstrated by the reduced liver tissue damage and steatosis, reduced hepatic lipid deposition and significantly improved liver biochemical function. However, the precise mechanism underlying the detailed role of each component of CQJD warrants further investigation.

Currently, the treatment of NAFLD is divided into three main categories: one is lifestyle changes, such as dietary adjustments, and increased physical activity; the second is control by clinical drugs; and the third is surgical intervention [3,12,34]. For the patient as a whole, changes in diet, energy intake control and increased exercise are still the first-line choice. Studies have shown that a 5-10\% decrease relative to the original body weight can effectively improve steatosis, but there is no definite evidence of an improvement in inflammation and fibrosis. In drug research, some progress has been made so far. Orlistat, a gastrointestinal lipase inhibitor, has been used to assist in weight loss. Orlistat was also used in the treatment of some NASH patients, but histologically did not improve [41]. Recently, studies on drugs such as GLP-1 receptor agonists [42] and DDP-4 inhibitors [43] have increased. Several studies have shown that the benefits of these two drugs for NAFLD outweigh the disadvantages. A study confirmed that Probucol can effectively reduce the ALT and HDL levels in patients with NASH, however, the exact effect remains to be determined [44, 45]. Vitamin E has been recommended for patients with NASH but not for those with diabetes [46, 47]. Some natural herbal extracts have proven to be beneficial to the liver; for example, silymarin, which has been shown to have a broad anti-inflammatory effect on the liver, including inhibition of neutrophil transfer and activation of Kupffer cells $[48,49]$. In summary, traditional Chinese medicine can play a beneficial role in the prevention and treatment of NAFLD and NASH, in the absence of effective drugs. Additionally, further study of traditional Chinese medicine still needs to be further carried out.

In conclusion, the present data confirm the therapeutic roles of CQJD in HFD- and MCD diet-induced NASH by alleviating steatosis, reducing inflammatory cytokine production and activating Kupffer cells. Our data indicate that CQJD may represent a promising new avenue for the treatment of NASH. However, the mechanistic importance of CQJD in the activation of Kupffer cells in NASH needs further study because this information could provide a more accurate therapeutic pathway for this common liver disease. 


\section{Cellular Physiology Cell Physiol Biochem 2018;48:971-982 and Biochemistry Publisned ontune: July 23, $2018 \quad \begin{aligned} & \text { DOI: 10.1159/000491965 } 2018 \text { The Author(s). Published by S. Karger AG, Basel } \\ & \text { www.karger.com/cpb }\end{aligned}$ \\ Cheng et al.: Cangju Qinggan Jiangzhi Decoction Inhibits NASH Development}

\section{Acknowledgements}

This work was funded by Outstanding Leaders Training Program of Pudong Health Bureau of Shanghai (Grant No. PWRL2016-01) and "TCM hepatology" key discipline construction projects (PWZxk2017-30).

\section{Disclosure Statement}

The authors confirm that there are no conflicts of interest.

\section{References}

1 Patel YA, Imperial JC, Muir AJ, Anstee QM, DeBrota D, Dimick-Santos L, Filozof C, Mehta R, Sanyal AJ, Schabel E, Neuschwander-Tetri BA, Miller V, Liver Forum's Data Standardization Working G: Baseline parameters in clinical trials for nonalcoholic steatohepatitis: Recommendations from the liver forum. Gastroenterology 2017;153:621-625.

-2 Alonso C, Fernandez-Ramos D, Varela-Rey M, Martinez-Arranz I, Navasa N, Van Liempd SM, Lavin Trueba JL, Mayo R, Ilisso CP, de Juan VG, Iruarrizaga-Lejarreta M, delaCruz-Villar L, Minchole I, Robinson A, Crespo J, Martin-Duce A, Romero-Gomez M, Sann H, Platon J, Van Eyk J, Aspichueta P, Noureddin M, Falcon-Perez JM, Anguita J, Aransay AM, Martinez-Chantar ML, Lu SC, Mato JM: Metabolomic identification of subtypes of nonalcoholic steatohepatitis. Gastroenterology 2017;152:1449-1461.

-3 Diehl AM, Day C: Cause, pathogenesis, and treatment of nonalcoholic steatohepatitis. N Engl J Med 2017;377:2063-2072.

-4 Gentilini A, Caligiuri A, Provenzano A, Marra F: Novel aspects in the pathogenesis of nonalcoholic steatohepatitis. Curr Mol Med 2016;16:710-720.

-5 Machado MV, Diehl AM: Pathogenesis of nonalcoholic steatohepatitis. Gastroenterology 2016;150:17691777.

6 Schattenberg JM, Lee MS: Extracellular vesicles as messengers between hepatocytes and macrophages in nonalcoholic steatohepatitis. Gastroenterology 2016;150:815-818.

7 Fan JG: Epidemiology of alcoholic and nonalcoholic fatty liver disease in china. J Gastroenterol Hepatol 2013;28:11-17.

8 Musso G, Cassader M, Paschetta E, Gambino R: Pioglitazone for advanced fibrosis in nonalcoholic steatohepatitis: New evidence, new challenges. Hepatology 2017;65:1058-1061.

-9 Cusi K: Nonalcoholic steatohepatitis in nonobese patients: Not so different after all. Hepatology 2017;65:47.

-10 Lou Y, Chen YD, Sun FR, Shi JP, Song Y, Yang J: Potential regulators driving the transition in nonalcoholic fatty liver disease: A stage-based view. Cell Physiol Biochem 2017;41:239-251.

-11 Sanyal AJ, Miller V: Regulatory science and drug approval for alcoholic and nonalcoholic steatohepatitis. Gastroenterology 2016;150:1723-1727.

$\checkmark 12$ Konerman MA, Jones JC, Harrison SA: Pharmacotherapy for nash: Current and emerging. J Hepatol 2017;68:362-375.

13 Wu YL, Zhu YB, Huang RD, Peng XE, Lin X: Multiple micrornas ameliorate hepatocyte steatosis and injury by suppressing fabp1 expression. Cell Physiol Biochem 2017;44:2243-2255.

14 Gomez Perdiguero E, Klapproth K, Schulz C, Busch K, Azzoni E, Crozet L, Garner H, Trouillet C, de Bruijn MF, Geissmann F, Rodewald HR: Tissue-resident macrophages originate from yolk-sac-derived erythro-myeloid progenitors. Nature 2015;518:547-551.

15 Heymann F, Tacke F: Immunology in the liver--from homeostasis to disease. Nat Rev Gastroenterol Hepatol 2016;13:88-110.

16 Tacke F, Zimmermann HW: Macrophage heterogeneity in liver injury and fibrosis. J Hepatol 2014;60:10901096. 


\section{Cellular Physiology Cell Physiol Biochem 2018;48:971-982 \begin{tabular}{l|l} 
DOI: 10.1159/000491965 & $\begin{array}{l}\text { O } 2018 \text { The Author(s). Published by S. Karger AG, Basel } \\
\text { www.karger.com/cpb }\end{array}$
\end{tabular} \\ Cheng et al.: Cangju Qinggan Jiangzhi Decoction Inhibits NASH Development}

17 Heymann F, Peusquens J, Ludwig-Portugall I, Kohlhepp M, Ergen C, Niemietz P, Martin C, van Rooijen N, Ochando JC, Randolph GJ, Luedde T, Ginhoux F, Kurts C, Trautwein C, Tacke F: Liver inflammation abrogates immunological tolerance induced by kupffer cells. Hepatology 2015;62:279-291.

18 Jenne CN, Kubes P: Immune surveillance by the liver. Nat Immunol 2013;14:996-1006.

19 Tacke F: Targeting hepatic macrophages to treat liver diseases. J Hepatol 2017;66:1300-1312.

-20 Krenkel O, Puengel T, Govaere O, Abdallah AT, Mossanen JC, Kohlhepp M, Liepelt A, Lefebvre E, Luedde T, Hellerbrand C, Weiskirchen R, Longerich T, Costa IG, Anstee QM, Trautwein C, Tacke F: Therapeutic inhibition of inflammatory monocyte recruitment reduces steatohepatitis and liver fibrosis. Hepatology 2018;1270-1283.

21 Han YH, Kim HJ, Na H, Nam MW, Kim JY, Kim JS, Koo SH, Lee MO: Roralpha induces klf4-mediated $\mathrm{m} 2$ polarization in the liver macrophages that protect against nonalcoholic steatohepatitis. Cell Rep 2017;20:124-135.

22 Mridha AR, Wree A, Robertson AAB, Yeh MM, Johnson CD, Van Rooyen DM, Haczeyni F, Teoh NC, Savard C, Ioannou GN, Masters SL, Schroder K, Cooper MA, Feldstein AE, Farrell GC: Nlrp3 inflammasome blockade reduces liver inflammation and fibrosis in experimental nash in mice. J Hepatol 2017;66:1037-1046.

23 Liu W, Baker RD, Bhatia T, Zhu L, Baker SS: Pathogenesis of nonalcoholic steatohepatitis. Cell Mol Life Sci 2016;73:1969-1987.

24 Larter CZ, Yeh MM: Animal models of nash: Getting both pathology and metabolic context right. J Gastroenterol Hepatol 2008;23:1635-1648.

-25 Dixon LJ, Flask CA, Papouchado BG, Feldstein AE, Nagy LE: Caspase-1 as a central regulator of high fat dietinduced non-alcoholic steatohepatitis. PloS one 2013;8:e56100.

-26 Tilg H, Moschen AR, Szabo G: Interleukin-1 and inflammasomes in alcoholic liver disease/acute alcoholic hepatitis and nonalcoholic fatty liver disease/nonalcoholic steatohepatitis. Hepatology 2016;64:955-965.

27 Zhang L, Schuppan D: Traditional chinese medicine (tcm) for fibrotic liver disease: Hope and hype. J Hepatol 2014;61:166-168.

28 Cheng F, Ma C, Wang X, Zhai C, Wang G, Xu X, Mu J, Li C, Wang Z, Zhang X, Yue W, Du X, Lian Y, Zhu W, Yin X, Wei Z, Song W, Wang Q: Effect of traditional chinese medicine formula sinisan on chronic restraint stressinduced nonalcoholic fatty liver disease: A rat study. BMC Complement Altern Med 2017;17:203.

29 Guo Y, Li JX, Mao TY, Zhao WH, Liu LJ, Wang YL: Targeting sirt1 in a rat model of high-fat diet-induced non-alcoholic fatty liver disease: Comparison of gegen qinlian decoction and resveratrol. Exp Ther Med 2017;14:4279-4287.

-30 Chen SD, Fan Y, Xu WJ: Effects of yinchenhao decoction (see text) for non-alcoholic steatohepatitis in rats and study of the mechanism. J Tradit Chin Med 2011;31:220-223.

31 Zhao SP, Wu ZS, Chen Y, Liang X, Bao L, Li P, Sun RR, Wu YL, Li LR, Wang Q: Protective effect of hua tan qu shi decoction against liver injury in rats with nonalcoholic fatty liver disease. Biomed Pharmacother 2017;91:181-190.

-32 Zhu M, Hao S, Liu T, Yang L, Zheng P, Zhang L, Ji G: Lingguizhugan decoction improves non-alcoholic fatty liver disease by altering insulin resistance and lipid metabolism related genes: A whole trancriptome study by rna-seq. Oncotarget 2017;8:82621-82631.

-33 Feng Q Gou XJ, Meng SX, Huang C, Zhang YQ, Tang YJ, Wang WJ, Xu L, Peng JH, Hu YY: Qushi huayu decoction inhibits hepatic lipid accumulation by activating amp-activated protein kinase in vivo and in vitro. Evid Based Complement Alternat Med 2013;2013:184358.

-34 Eslam M, Valenti L, Romeo S: Genetics and epigenetics of nafld and nash: Clinical impact. J Hepatol 2017;68:268-279.

35 Gluchowski NL, Becuwe M, Walther TC, Farese RV, Jr.: Lipid droplets and liver disease: From basic biology to clinical implications. Nat Rev Gastroenterol Hepatol 2017;14:343-355.

36 Rajman L, Chwalek K, Sinclair DA: Therapeutic potential of nad-boosting molecules: The in vivo evidence. Cell Metab 2018;27:529-547.

37 Mukhopadhyay P, Horvath B, Rajesh M, Varga ZV, Gariani K, Ryu D, Cao Z, Holovac E, Park O, Zhou Z, Xu MJ, Wang W, Godlewski G, Paloczi J, Nemeth BT, Persidsky Y, Liaudet L, Hasko G, Bai P, Boulares AH, Auwerx J, Gao B, Pacher P: Parp inhibition protects against alcoholic and non-alcoholic steatohepatitis. J Hepatol 2017;66:589-600. 


\section{Cellular Physiology Cell Physiol Biochem 2018;48:971-982

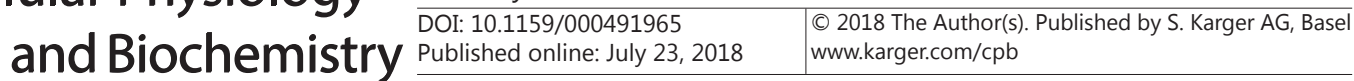 \\ Cheng et al.: Cangju Qinggan Jiangzhi Decoction Inhibits NASH Development}

-38 Cai C, Zhu X, Li P, Li J, Gong J, Shen W, He K: Nlrp3 deletion inhibits the non-alcoholic steatohepatitis development and inflammation in kupffer cells induced by palmitic acid. Inflammation 2017;40:18751883.

39 An Y, Liu X, Qian Q, Zhang D, Li Y, Gao X, Zhang Y, Wang T: Triglyceride accumulation: Inhibitory effects of tangzhiqing formula. Altern Ther Health Med 2013;19:20-29.

40 Luo X, Xu X, Huang C, Wu X, Liu J, Lan B, Xu J: [experiment study of total anthraquinone in cassiae semen on lipid peroxidation and ppar-gamma expression in liver tissues of rats with alcoholic fatty liver]. Zhongguo Zhong Yao Za Zhi 2011;36:1654-1659.

-41 Rotman Y, Sanyal AJ: Current and upcoming pharmacotherapy for non-alcoholic fatty liver disease. Gut 2017;66:180-190.

42 Petit JM, Verges B: Glp-1 receptor agonists in nafld. Diabetes Metab 2017; 43:2S28-22S33.

43 Ndefo UA, Okoli O, Erowele G: Alogliptin: A new dipeptidyl peptidase-4 inhibitor for the management of type 2 diabetes mellitus. Am J Health Syst Pharm 2014;71:103-109.

44 Ishitobi T, Hyogo H, Tokumo H, Arihiro K, Chayama K: Efficacy of probucol for the treatment of nonalcoholic steatohepatitis with dyslipidemia: An open-label pilot study. Hepatol Res 2014;44:429-435.

-45 Merat S, Malekzadeh R, Sohrabi MR, Sotoudeh M, Rakhshani N, Sohrabpour AA, Naserimoghadam S: Probucol in the treatment of non-alcoholic steatohepatitis: A double-blind randomized controlled study. J Hepatol 2003;38:414-418.

-46 Lazaridis N, Tsochatzis E: Current and future treatment options in non-alcoholic steatohepatitis (nash). Expert Rev Gastroenterol Hepatol 2017;11:357-369.

47 Caldwell S: Nash therapy: Omega 3 supplementation, vitamin e, insulin sensitizers and statin drugs. Clin Mol Hepatol 2017;23:103-108.

48 Wah Kheong C, Nik Mustapha NR, Mahadeva S: A randomized trial of silymarin for the treatment of nonalcoholic steatohepatitis. Clin Mol Hepatol 2017;15:1940-1949.

49 Ni X, Wang H: Silymarin attenuated hepatic steatosis through regulation of lipid metabolism and oxidative stress in a mouse model of nonalcoholic fatty liver disease (nafld). Am J Transl Res 2016;8:1073-1081. 